International Journal of Child, Youth and Family Studies (2014) 5(1): 180-203

\title{
THINKING THE OTHER SIDE OF YOUTH SUICIDE: ENGAGEMENTS WITH LIFE
}

\author{
Scott Kouri and Jennifer White
}

\begin{abstract}
Despite a vast and growing body of published empirical literature on this topic and a recent profusion of new prevention programs, suicide continues to be the second leading cause of death among young people in Canada. Current knowledge about preventing suicide and suicidal behaviours among youth is extremely limited and thus the call for greater diversity and creativity in our theories and practices is more vital than ever. The purpose of this article is to open up new spaces for critical and innovative thinking about suicide and suicide prevention, with a particular focus on youth populations and those who work with youth. Post-structural theory is mobilized in the critique of dominant biomedical conceptualizations of suicide in order to create new spaces for thinking suicide otherwise, and to mobilize opportunities for youth to think with adults in the exploration of life affirming alternatives. Working against any final or authoritative impulse to determine "what suicide is", we draw on theoretical and ontological frameworks that privilege difference, complexity, multiplicity, movement, and contradictions. This article is an invitation to engage with life in its creative, playful, and affirmative character; to seek joy, hope and a future in thinking suicide otherwise.
\end{abstract}

Keywords: suicide, suicide prevention, critique, youth, prevention, post-structuralism

Acknowledgements: The authors are extremely grateful for the helpful comments from one of the anonymous reviewers who challenged us to deepen and sharpen our analysis. We believe it has enhanced the piece considerably.

Scott Kouri is a graduate student and is currently working as a Teaching Assistant in the School of Child and Youth Care (CYC) at the University of Victoria, Victoria, British Columbia, Canada. He is also a Term faculty member at Camosun College in Victoria. Trained as a counsellor and youth worker, Scott is interested in how concepts of the self, identity, and subjectivity are circulated in curricula and enacted in praxis. E-mail: skouri@uvic.ca

Jennifer White, Ed.D., co-editor of the International Journal of Child, Youth and Family Studies, is an Associate Professor in the School of Child and Youth Care, University of Victoria, P.O. Box 1700, STN CSC, Victoria B.C., Canada, V8W 2Y2. E-mail: jhwhite@uvic.ca 
School- and community-based youth suicide prevention programs have proliferated in recent years, and despite a vast and growing body of published empirical literature on this topic, suicide continues to be the second leading cause of death among young people in Canada (Statistics Canada, 2012). Current knowledge about preventing suicide and suicidal behaviours among youth is extremely limited and thus the call for greater diversity and creativity in our theories and practices is more vital than ever. The purpose of this article is to open up new spaces for critical and innovative thinking about youth suicide and youth suicide prevention. Rather than continue on the familiar path of seeking greater precision in our ability to detect risks for suicide, this paper is an invitation to engage with life in its creative, playful, and affirmative character; to seek joy, hope, and a future in thinking suicide otherwise.

Importantly, this article is not about providing authoritative answers to the question of why young people take their own lives. We do not here aim to synthesize the current research evidence nor do we conclude with a series of "how to" steps for reducing risks for suicide. In the aftermath of Port Coquitlam teenager, Amanda Todd's suicide (Dean, 2012), an event which generated worldwide attention and amplified public concerns about bullying and suicide among young people, this disavowal of clarity and "solution talk" may come as a surprise, and yet, it is precisely this turn towards unworn paths and a repudiation of the familiar that we are after. In other words, we want to raise questions about the antecedents and consequences of "having knowledge about suicide”, and explore some possibilities for thinking suicide otherwise.

Working against any final, authoritative, singular, or essentializing determination of "what suicide is", we aim to think with alternative theoretical and ontological frameworks that privilege difference, complexity, multiplicity, movement, and contradiction. We mobilize poststructural theory to critique dominant biomedical conceptualizations of suicide that automatically link suicide to psychopathology - what Marsh (2010) refers to as a "compulsory ontology of pathology" (p. 28). We raise suspicions about those technologies of prevention that are preoccupied with calculation, pre-emption, and control (Diprose, 2008). In short, we seek to question prevailing "truths" about youth suicide prevention practices and identify a number of theoretical, ontological, and practical resources for thinking through alternatives. In contrast to the prevailing masculinist reading of suicide (Jaworski, 2003), which is predicated on notions of individual autonomy, choice, and seriousness of intent, we attempt to engage with suicide in its multiple, discursive, historical, material, relational, and performative character (Jaworski, 2010; Marsh, 2010). This joint effort to "think the other side of suicide" exposes sedimented and takenfor-granted knowledges about suicide prevention and offers a different starting point for future discussions.

\section{Theoretical Trajectories: Genealogy, Deconstruction, and Ontology}

This article is organized into five distinct parts. We begin with an introduction to poststructuralist ideas and briefly highlight the work of others who have adopted this theoretical frame in the analysis of suicide and suicide prevention practices. Secondly, to understand how dominant views of suicide have emerged within contemporary Western culture, we turn to the work of Ian Marsh (2010) who uses Foucault's genealogical method to trace the history of our knowledge of suicide and the emergence of the suicidal subject as an object of scientific knowledge. We trace how suicide has been conceptualized from classical antiquity, through 
Christianity and the Middle Ages, to the psychological and increasingly biomedical discourses of contemporary Western culture. This historical mapping demonstrates the contingent and political nature of our knowledge and reminds us that things could have always been otherwise.

Thirdly, inspired by Jacques Derrida (1967/1976), we work in a deconstructive mode to demonstrate that within contemporary medicalized discourses, both the term and concept “suicide” operate to exclude variable meanings related to ending one’s own life. Derrida’s (1967) notion of différance helps us to explore how any term or concept, in this case suicide, is always endlessly referring to, and differing from, itself and other words and concepts rather than to any stable, singular, or essential event or person outside language. Words such as "suicide" cannot, from this perspective, be used to point directly to things in the world but rather operate by referring to clusters of associated words while attempting to exclude other associations. We argue that our language and language practices work to produce what and how we come to think of the real things of existence, such as "a suicidal youth".

Fourthly, to support our position that knowledge of suicide is not innocent, objective, stable, or ahistorical, we turn to cross-cultural, historical, and philosophical understandings of suicide. The examples we highlight include the following: self-immolation and self-sacrifice; suicide as a response to hate and other intolerable conditions, such as settler colonial relations on Indigenous lands; and suicide as a philosophical problem. Importantly, each example disrupts the tendency to reduce all acts of self-accomplished death to internal psychopathology. As unfinished projects, they each contain within them some latent creative potentialities for thinking and being otherwise.

Throughout the paper we maintain the seemingly paradoxical stance that it is the very attempt to prevent and control differences, anomalies and death, that life itself, in all of its creative and unpredictable character, is smothered. To offer at least one alternative framework for conceptualizing how thinking otherwise about suicide might proceed, in the fifth and final section we turn to Gilles Deleuze, Felix Guattari, and Rosi Braidotti who help us think through affirmative conceptualizations of difference and becoming. Deleuze and Guattari (1972/2000) ground difference, anomaly, and play in the very substance of existence: an ontology of creation, vitality and life expressed differently; or an ontology of immanence. ${ }^{1}$ By recognizing that existence is difference and flux, Deleuze and Guattari (1972/2000, 1980/2004) open up new possibilities for actively engaging in projects of living and transformation. From an ontological position of immanence and difference, our subjectivities do not exist prior to the entanglements of materiality, affect, thinking, and history; rather, "we" are produced as expressions of a life force that is perpetually configuring itself anew. Thus, it is our limitless capacities for connection and transformation within this flow, and the possibility for our thought to become different, which are life affirming and express our unique capacities most fully. Deleuze and Guattari's immanent ontology helps us to think about how reality can be conceptualized as a vital and flowing plane of forces, which create, connect, shatter, and produce ever-changing and kinetic entity-experiences. The view of life as multidirectional movement, creation, indeterminacy, and fluctuation is the force that we hope to think with and infuse into the field of suicidology and the practice of youth suicide prevention.

\footnotetext{
${ }^{1}$ Deleuze and Guattari's ontology of immanence builds on a long lineage of Western philosophical thought dating
} back to the $17^{\text {th }}$ century philosopher Baruch Spinoza (Deleuze \& Guattari, 2003). 
In sum, our hope is to locate new starting points and identify unexplored ethical dimensions in thinking suicide otherwise. These include, for example: practicing in ways which affirm life in its perpetually transforming character; believing that youth have the capacity to critique current regimes of truth and create new concepts that better serve them; understanding how language, knowledge and life are intricately related; and taking responsibility for the relational practices that are enacted through our notions of care. The ultimate goal of this project is to open youth suicide prevention to its own future, by engaging in what Caputo (1997) describes as "keeping thinking and writing alive, keeping them open to surprise, by keeping on the alert to the institutions in which they are housed" (p. 62). We work from the assumption that life is on the move and perpetually producing itself in novel configurations. We work at "thinking suicide otherwise" as a way to resist the strangling and stifling discourse of suicide and youth suicide prevention, and move instead towards an affirmative and affective experimentation with a life worthy of its name.

\section{Post-structural Theory, Care, and the Concept of Suicide}

A range of diverse thinkers, themes, and approaches have been grouped in the past 40 years under the term post-structuralism. Although the diversity across these thinkers and theories generally outpaces their similarities, the term post-structuralism, as a critique of structuralism and an extension of critical theory, has taken hold. Important theoretical components of most post-structural theory include a reconsideration of the role and interconnection of language and discourse; subjectivity; power and freedom; truth, knowledge, and rationality. Post-structural theory helps us to reconsider subjectivity in relation to language and power. Subjectivities, such as the "suicidal individual" or "the professional" for example, are not theorized to exist in some essentialist way outside of language, but rather understood through ongoing processes of subjectification, objectification, and other socially constitutive practices that are embedded in discourse. Foucault $(1978,1976 / 1980)$ argued that discourses (i.e., a system of language and practices that circulate and are enacted within a particular regime), structure subject positions and relations of power. Subject positions, such as "the suicidal" and "the professional", are taken up or assigned based on political and historical circumstance rather than being predicated on any internal, intrinsic, or essential qualities of being. Once a cultural discourse, such as the biomedical, circulates with sufficient power, subject positions such as "the sick", "the at-risk", and "the expert" become severely restrictive, prescriptive, and constitutive. Discourses actively shape and limit how we come to think of individuals, including carers and those who receive care, and how they are positioned in relation to one another. For the purposes of this article, we are interested in exploring how professional helping, expert knowledge, and suicidal subjects have emerged within historical relations of power and knowledge, and what alternatives are available. Based on post-structural understandings of subjectivity and discourse, opportunities for envisioning alternatives or resistance to the dominant regime are not always clear. This article is an experiment in this regard.

We are of course not the first in the field of suicidology to call for "new freedoms of thought and action in place of those that have come to be constraining and problematic in themselves” (Marsh, 2010, p. 8). Building on the important work of others, such as Range and Leach (1998), who have recognized the inherent limits of relying on a narrow range of 
methodologies for studying suicide and its prevention, we also seek to dislodge the dominant positivist paradigm and realist ontology that permeate the field of suicidology today.

For example, Fox (1995) draws on a variety of post-structural philosophers to understand how the concept of "care”, especially professional care, can be seen as both "vigil” and "gift". Enacted as vigil, care is about power, especially power associated with knowledge, control, surveillance, and professional intervention. At the same time, Fox also recognizes the availability of another discourse, care-as-gift, which is centrally concerned with generosity, trust, love, and, of particular significance here, difference. ${ }^{2}$ Importantly, these two enactments of care are not mutually exclusive or even possible without each other.

Fullagar (2003) also utilized a post-structural analysis to interrogate how neo-liberal discourses, with their emphases on effective self-management and economic productivity, position life as an object that "the entrepreneurial self must maximize in value” (p. 292), which has implications for how suicide might be understood. Within contemporary economies of value, suicide often becomes read as the actions of a "failed self" or a process of "becoming waste".

In a nursing context, Stephenson and Cutcliffe (2006) draw on Foucault to analyze mainstream practices of "special observation" a surveillance technique used by professionals to closely monitor those at risk for suicide. Their analysis highlights the relationship between practices of categorization and objectification which identity certain patients as is in need of control. Jaworski (2010) also draws on Foucault to consider complex questions of agency, choice, deliberation, and authorship in relation to the "taking of one's life”. By conceptualizing suicide as relational and performative, she suggests that the intention of suicide can never be original nor entirely individual "because suicide has a discursive history that conditions the meaning of a particular bodily gesture” (p. 680). Jaworski (2003) also highlights the ways in which suicide is a highly gendered act, whereby the specific rituals and gestures through which suicide comes to be constituted, including for example thinking about it, writing a note, acquiring the means to kill oneself, planning the location, and waiting for unconsciousness following the enactment, are always already interpreted from a gendered discourse (e.g., active/passive method; serious/not serious intent). It is from within these multiple post-structural currents that we hope to keep thinking, practicing, and living otherwise. Ian Marsh's (2010) book, Suicide: Foucault, History and Truth, is a key inspiration in this regard and we will begin with his work.

\footnotetext{
2 Although beyond the scope of this paper, we would like to direct the interested reader to Derrida's $(1992,1995)$ writings on "the gift" and "death" which elaborate the aporetic relationship between the two and how this relationship establishes an ethics of responsibility which oscillates between the particular and the universal in every situation. Derrida's (1992) Given Time discusses the impossibility of the gift in terms of its reliance on a past and future, as well as its invocation of return, obligation, memory, exchange, acknowledgement, and compensation, thereby making any present or pure gift impossible. In The Gift of Death (1995) Derrida argues for an ethics of responsibility to the other, which is impossible because of our responsibility to every singular other (a singularity which the apprehension of death makes possible) conflicts with our responsibility towards all others. Derrida takes up the gifts of death, murder, sacrifice, suicide, and so on, to argue that they are always impossible as pure gifts and therefore always beyond decision in terms of an ethics of responsibility.
} 
International Journal of Child, Youth and Family Studies (2014) 1: 180-203

\section{Genealogy of Suicide}

Of particular interest to us is the way that Marsh (2010) draws on the concept of ontology to highlight the contemporary regime of truth related to suicide. Ontology is the branch of philosophy concerned with what there is (Law, 2004), or the study of existence more generally (May, 2005). Marsh argues that suicide and suicidal behaviours are now almost always explained by referencing individual mental disorders or psychopathological processes, a condition that he describes as a "compulsory ontology of pathology" (p. 28). Risk and pathology are understood within this framework as located within individual persons who require expert treatment and professional interventions. Drawing on Foucault, Marsh historically maps current discourses of suicide by tracing the conditions of possibility that enabled its emergence, circulation, and enactment. He also highlights its instability over time and analyzes how suicidal subjectivities and knowledge of suicide are formed in relation to each other and ultimately made intelligible through particular practices. Knowledge of suicide, from this perspective, is thus an effect of power whereby certain groups of people are authorized to "tell the truth" about suicide. For example, a medicalized discourse of suicide produces specific subjectivities such as "the expert", "the professional", "the researcher", and "the suicidal patient" or "client", wherein the expert, the professional and the researcher are authorized to explain and enforce the "truth" of the other.

Marsh (2010) maps some of the historical relations of power which have shaped the subjects and objects of suicide, including suicidal individuals and suicide itself. He demonstrates how suicidal subjects of today have come to be understood through a range of technologies, expert pronouncements, and truth effects which collectively impose a limit on what can be thought, said, or done. As a consequence, alternative ways of knowing, approaching, and being in relation to suicide are silenced. Marsh (2010), following Foucault, calls these marginalized ways of knowing "subjugated knowledges" (p. 72). Subjugated knowledges are ways of knowing about suicide and being in relation to others which have been silenced by the dominant discourse but which continue to inhabit the margins of the compulsory ontology. In the following section we consider alternative and subjugated knowledges about suicide via Marsh's genealogy while also highlighting the historical contingencies which have helped to shape our current conceptualizations.

\section{Suicide as Historically Contingent}

Marsh (2010) begins his genealogical analysis in classical antiquity where, he argues, the concept of suicide as understood today had no equivalent. The closest Latin counterparts to our "suicide" included phrases better translated as: voluntary death; destroying oneself; taking the last measure; and striving after death. In contrast to the homogenous and singular understanding of suicide expressed through the Western biomedical model, subtle variations in vocabulary provided the linguistic resources necessary to attribute different meanings to seemingly similar phenomena in classical Rome and Greece. These different articulations of self-accomplished death brought attention to its relational, philosophical, and political character. For example, in early Rome, self-accomplished death was inconceivable without reference to notions of honour, social status, and the political system. Furthermore, an equivalent to the suicide specialist or 
counsellor in classical Rome might be an eminent relation who provided spiritual guidance as the body of the soon to be deceased was being separated from his immortal soul. ${ }^{3}$

Marsh (2010) goes on to survey the history of suicide in early Christianity and demonstrates how the emerging Christian church responded to a pervasive culture of martyrdom by instituting a moral climate that favoured the prohibition of suicide. Gradually this process continued until the time when Augustine condemned self-accomplished death as a violation of the sixth commandment and therefore a mortal sin. Murray (1998b) details, for example, how following Constantine's conversion, when the church and state converged for the first time, new sets of moral and ethical challenges emerged. A tension grew between martyrdom and "selfhomicide" which forced the church to examine the differences between the two. This became particularly relevant when the Donatists claimed that their persecutions at the hands of the empire, including penalties of death, were actually a path to martyrdom mirroring early Christian self-abandonment to the early Romans (Murray, 1998b). Augustine, a century after Constantine, responded to the particular challenge of self-accomplished death by condemning suicide as repudiating the will of God: a view that would hold for centuries. Over time, the Church would formalize penalties for suicides such as refusing burial on consecrated soil.

The discourse and practices related to self-murder continued to morph along historical and political lines throughout the centuries, particularly as the political climate of Western civilization shifted more towards one of sovereign rule (Marsh, 2010). Suicide as a rejection of God's will gradually became interpreted as a rejection of sovereign will. Foucault (1978) explains that, "one of the characteristic privileges of sovereign power was the right to decide life and death” (p. 135). As a right to take life, or rather to suppress it, the sovereign's power was one of seizure and deduction. Gradually the penalties of sin became replaced by, or at least coincided with, the penalties of law.

By the 17th century, with the rise of legal inquests, investigations became common and self-accomplished death was approached through information gathering, an analysis of method, the summoning of witnesses, and the judgement of a court. Persons could now be found to be "felons of themselves" and guilty of self-murder or, alternatively, non compos mentis (not of sound mind). Being found guilty of the crime of self-murder became punishable by loss of property for the surviving family. Murray (1998a) explains that, “conceptually, the difference between acts committed by a sane and by an insane person was clear-cut. One was criminal, one not: it depended on whether an act of conscious will was involved” (p. 164). Now clergy, family members, religious orders, and officers of the law came to bear on decisions of culpability, sanity, crime, and punishment.

From the end of the 17th century onwards, a shift from punishment to confinement and treatment of the suicidal person could be discerned (Marsh, 2010). New medical "truths" about suicide, which conflated suicide with madness, contributed to the emergence of new subject

\footnotetext{
3 The notions of suicide and the immortal soul in classical antiquity cannot be adequately understood without a consideration of Platonic idealism or, at a minimum, Plato's Phaedo, which recounts the last days of Socrates. For the purposes of this paper we are briefly summarizing some of Marsh's (2010) genealogical work on suicide in order to argue for the importance of freedom to think suicide otherwise. For the reader interested in Greek thought, we suggest M. Murray (2001) and A. Murray (1998b) for more on Plato, Platonic idealism, and suicide.
} 
positions: the "suicidal patient" and the "doctor". Interestingly, according to Tatz (2001), glimpses of the medical model could be inferred as early as the 1600s, but it was in the 1870s when lawyers invented protective laws to prevent loss of property and right of burial that suicide and sickness were inextricably wedded. Tatz suggests that, "it would be sensible to remember that the lawyers, not the doctors, devised the notion, and the fiction, that suicide occurred because 'the balance of his mind was disturbed'” (p. 37). No longer seen as a perpetrator of a sin or crime, the suicidal person became coded as sick, ill, imbalanced, or diseased, and unable to bear total responsibility for his or her actions. Instead, there was a growing class of experts and other authorities expected to take on increasing responsibility for preventing, what was now considered to be an unnecessary, avoidable, and preventable death.

The growing symbiotic relationship between medicine, madness, suicide, and the sick body led quickly to "a proliferation of discourses and associated technologies concerned with identifying, examining, confining, watching, restraining, diagnosing and treating the suicidal” (Marsh, 2010, p. 99). Kushner (1986) shares an example from an 1845 medical report that describes an American man of poor health who gradually became melancholic and twice attempted suicide. The man was committed to a lunatic asylum and there received warm baths, laxatives, and tonics to restore his health. Two months later he returned home cured. Kushner explains how 19th century psychiatrists became increasingly preoccupied with classifying symptoms and diseases in the hopes that "statistical analyses of categorized groups of symptoms would lead to an understanding of causation. Because of its finality, suicide especially lent itself to nosological methodology and statistical analysis” (p. 41). In the 19th century, suicide was clearly understood as a form of individual psychopathology; however, Kushner (2009) explains that understanding of suicide etiology was still mixed and many unanswered questions regarding the consequences of urbanization and modernity remained.

Marsh (2010) also draws on Foucault's concept of bio-power to explain how specific practices, politics, and technologies emerged to manage the health of large urbanized populations through the maximization of the health of individual bodies. Foucault (1978) conceptualizes these bio-political processes in terms of the disciplining of bodies and the optimization of their capacities for integration into economic systems, as well as a political regulation of the population through administrative means and surveillance. In contrast to the sovereign's power to deduct life, Foucault argued that a transformation took place in Western society that featured "the right of the social body to ensure, maintain, or develop its life" (p. 136). Bodies, through productive apparatuses, became instruments in the development of capitalism, requiring a docility that made governing and optimizing them less complicated.

By mid-19th century, psychiatry and medial discourse flourished as risks and dangers related to the entire social body were increasingly enfolded within their scope or practice (Marsh, 2010). Individual bodies, if perceived as a threat to the prevailing social order, could be justifiably confined or subjected to medical intervention. Bio-power, in this sense, managed the health, productivity, and efficiency of the population as a whole through the discipline of individual bodies. Foucault (1978) designates bio-power as "what brought life and its mechanisms into the realm of explicit calculations and made knowledge-power an agent of transformation of human life" (p. 143). By the end of the 19th century, the idea that suicidal behaviours required expert intervention from medical practitioners went largely uncontested. 
Biopolitical technologies of prevention (Diprose, 2008), including those focused on the prevention of youth suicide, continue to this day and are designed to ensure the correct categorization, regulation, and management of those who have been identified as "at risk". These discourses, which have been described by Diprose as a paradigm of pre-emption, often generate a fearful stance in relation to the future while simultaneously pointing towards the achievement of an unnamed, more desirable, future self. For the most part they are predicated on the assumption that all uncertainties and human contingencies can be predicted and controlled.

Conceptualizations of suicidal behaviours as a form of pathology were maintained over time and, with the rise of psychoanalysis, became relocated from the body of the individual to their internal psyche. In other words, the treatment of suicidal persons was no longer restricted to the confinement, surveillance, and regulation of bodies within the asylums: Suicidal thoughts and behaviours could now be properly addressed through various "talking cures" and psychological interventions (Marsh, 2010). Confession, self-disclosure, and self-monitoring became the new forms of therapeutic engagement and heralded the emergence of a whole array of "psy" discourses (i.e., psychology, psychoanalysis, and psychotherapy) which persists in many forms today (Rose, 1999). According to Rose, these new "experts of subjectivity" and "managers of the soul” are emblematic of what Foucault referred to as pastoral power:

Through self-inspection, self-problematization, self-monitoring, and confession, we evaluate ourselves according to the criteria provided for us by others. Through selfreformation, therapy, techniques of body alteration, and the calculated reshaping of speech and emotion, we adjust ourselves by means of the techniques propounded by the experts of the soul. (p. 11)

\section{Subjugated Knowledges}

Throughout history, and with the rise of the "psy" discourses, many other forms of knowledge about suicide were erased or “subjugated”. Foucault's concept of subjugated knowledges posits that throughout history diverse knowledges have been suppressed to maintain the coherence of the dominant system and that these knowledges are available in the margins of dominant knowledge for tactical use today (Foucault, 1976/1980). For example, what is normally considered scientific truth in a culture largely depends on a hierarchy of knowledge that marginalizes alternative knowledge claims. These marginalized knowledges, Foucault argues, bathed in a history of hostile encounter, provide the counter-position to dominant knowledges.

The re-circulation of marginalized knowledge, or what Foucault (1976/1980) calls the "insurrection of subjugated knowledges" (p. 81), offer new possibilities for producing objects of knowledge and alternative subjectivities. These knowledges and subjectivities, however, are always at risk of being appropriated and recolonized by the dominant truth-regime. In this sense, Foucault's early conception of the subject as totally inscribed by discourse and "of a self which is nothing more than the construction of power/knowledge, leaves a problem for theorising resistance to discourse" (Fox, 1995, p. 115). On the one hand, a subject is fully constituted by discourse; while on the other hand, the recirculation of subjugated knowledges provides spaces for resistance and new forms of subjectivity. 
Rather than advocate for one or another of the subjugated ways of understanding suicide, this paper works to elaborate and circulate the very multiplicity of knowledges in an ethic of resistance (Reynolds, 2008) and in support of an unknown and open future. On the one hand, previously subjugated knowledges contain the revolutionary potential to rupture the suffocating dominance of the ontology of compulsory pathology, while on the other hand, these ruptures are specifically that: cracks and counter-forces, where new forms of knowledge and life may grow. In our current context, where biomedical models dominate yet fail to achieve their targeted goal of understanding, predicting, and preventing youth suicide, we venture the thought that the recirculation of foreclosed understandings about self-accomplished death may open up spaces to rethink suicide and offer alternative subject positions for youth and practitioners alike.

Furthermore, we venture the more risky thought that youth themselves have the capacity to use these knowledges to produce lives, futures, and worlds worth living.

\section{Implications for Practice and Pedagogy}

Our analysis of the knowledge practices related to suicide thus far gestures towards the productive possibilities that might emerge when we do not rely on expert pronouncements or final meanings about suicide. Particularly, we are curious about the possibilities for engaging young people in conversations about suicide and their own projects of living. In other words, rather than positioning youth as passive recipients of expert knowledge about suicide and imposing limits on what may or may not be thought or said, we might instead consider engaging them in ways that position them as a creative life force capable of freely generating possible futures (which may, of course, include negotiating suicide).

This way of working and thinking moves us from assessments and expert interventions towards affirming life's generative capacities. In an educational context, this could include for example, inviting young people to be curious about the multiple ways in which suicide has been made intelligible over time and across cultures. We wonder what it would be like to track suicide through history with young people. For example, what happens when we think about suicide as something other (or more) than a singular, timeless or universal category? When viewed through the lens of history, what is potentially left out of our contemporary understandings of suicide? Who benefits most from the descriptions and vocabularies that are currently available? Who benefits the least? What subject positions become available when we are exposed to a historical mapping of suicide? What are some new ways that suicide might be conceived? What novel ways might be available to engage with death, loss, life, and future?

By considering various public accounts of youth suicide (here in Canada this could include the recent high profile coverage of the suicide deaths of Amanda Todd and Ashley Smith ${ }^{4}$ ), youth could be invited to examine the ways that these suicides are socially constructed; the strategies that are used to produce explanations; the silences, gaps and things left unsaid; as

\footnotetext{
${ }^{4}$ See for example http://fullcomment.nationalpost.com/2012/11/08/christie-blatchford-ashley-smiths-prison-guardsin-shroud-of-misdirection-and-fear/ or http://www.guardian.co.uk/commentisfree/2012/oct/26/amanda-toddsuicide-social-media-sexualisation
} 
International Journal of Child, Youth and Family Studies (2014) 1: 180-203

well as the effects of various youth suicide prevention messages and practices. After carefully considering a range of ways for thinking suicide otherwise, young people could be supported in designing local, affirmative and life enabling projects of their own. As we stated in our introduction, it is not our intention to offer ready-made solutions. Rather, we are interested in how we might resist the productive and disciplinary effects that constitute all of us in essentialized ways, including, for example, as professionals, experts, and at-risk or suicidal youth. More than this, we wonder what might come of engaging young people around the historical, political, discursive, and cross-cultural dimensions of suicide. What spaces might we open up by placing the tools of critical analysis in the hands of young people and what might young people do with that space? What might happen if our practices started, not only by decentring our expert knowledge, but also by jointly critiquing the knowledge which positions practitioners and youth in particular ways around the topic of suicide?

\section{"Suicide": the Very Word!}

Where Foucault challenges truth claims on the historical and politically charged grounds of our knowledge, Derrida challenges the attempt of using representational language to capture a reality outside of it (May, 2005). Derrida (1967/1976) critiques and extends traditional linguistics (de Saussure, 1959), which proposed that a linguistic sign is composed of a signifier (word or sound image) and a related signified (concept). [D]e Saussure proposed that the relationships of the signifiers were arbitrary (there being no necessary reason that we use a particular sound image to represent a particular concept) and differential (they attain a value based on their simultaneous presence and difference with other signifiers in a system). Although Derrida grants that the value of any sign is based on its relation to other signs, he also argues that systems of signs are neither stable nor present to themselves and therefore cannot provide consistent meaning.

A traditional linguistic account of the term "suicide" would posit that the signifier (sound image: "suicide") represented some concept (signified) in an arbitrary and differential way. The signifier "suicide" has a non-necessary relationship to the signified concept and attains meaning in its differential relation to other associated signifiers such as "homicide”, "natural death", "martyr”, etc. (rather than pointing positively to something in external reality). Derrida's (1967/1976) critique of the simultaneous presence of a linguistic system exposes how any of the signs used to attain a value for a sign, in our case "suicide", are themselves endlessly calling upon other signs to substantiate them and therefore postponing meaning indefinitely. The meaning of "suicide" for example, would rely on a meaning for "natural death" which would in turn rely on a meaning for "life", which would call for a definition of an "individual", and so on and so on.

Derrida (1967/1976) also puts emphasis on the spacing between associated terms and argues that rather than having decisive points which separate two signs, there is always an undecidability which disrupts clear differentiation and meaning and that one sign's meaning is always contaminated by multiple interpretive possibilities. Language, as with all else for Derrida, is in a dynamic state related to the past and future. There is no point at which any system, be it language or life, comes to a stop and is present to be counted and understood as a whole. We are born into a world of signs that are always, already on the move and always contaminated by 
International Journal of Child, Youth and Family Studies (2014) 1: 180-203

traces of other terms. Importantly, the use of the very term "sign” for Derrida (1966/1978) is a critique of the structure separating the intelligible and the sensible in any clear and stable way. We use the conventional term "sign" while reminded of Derrida's deconstruction of distinctions between signifier and signified, language and reality, nature and culture, and other binary pairs.

From a deconstructive perspective, therefore, the meaning of the signifier "suicide" and its related concept are perpetually deferred or put off. They are always open to reinterpretation depending on ever-shifting contexts. "Suicide" attains meaning, not by identifying something out in the world, but rather by its differential relationship with all the other signs in a contextualizing system. For example, "suicide" attains meaning through its relationship to signs such as "life", "natural death”, “suicidal ideation”, “homicide”, “accident”, “self-injury”, “attempted suicide”, "self-harm”, "sacrifice”, "psychosis”, “intentional and unintentional injury”, etc. Importantly, all these signs in turn derive meaning through further relationships, which are themselves always shifting, ad infinitum. No final, contained, present, or positive meaning for "suicide" will ever be available to us, but rather, what we do have is the jostling of different discourses for dominance over signifying practices. Contexts in this sense are stabilizing systems that serve to secure meanings through some form of structure or set of relationships. Derrida's insights help us to think about how medical discourse, as a context, attempts to stabilize the meaning of "suicide" in relation to other discursive constructions (e.g., “patient”, “at-risk”, “depression”, “prevention”).

Deconstruction works by showing how structures have been assembled, as well as how they are perpetually shifting and changing (Derrida, 1967/1976). Furthermore, through the examination of the multiple ways a signifier, in our case "suicide", has been used in a text, its paradoxes, exclusions, and complexities are unveiled. For the purposes here, it is the text of the "compulsory ontology of pathology", stabilized through the structures of academia, medical discourse, bio-power, government publications, scientific research, and interpersonal interaction, that is under deconstructive pressure. Medical discourses and the "compulsory ontology of pathology” repress or reduce the multiplicity, or play of signification related to self-induced deaths, and systematically work to reduce these deaths to a singular meaning. To resist such reductions and repressions, our sustained exploration of alternative discourses, knowledges, experiences, and meaning-making systems is aimed at mobilizing the play of difference related to "suicide". To begin with, mobilizing alternative codings of "suicide", such as "selfaccomplished death”, “voluntary death”, and “cancelling life”, helps us to trouble or reorient in relation to the singular and seemingly stabilized term "suicide". In this respect, we wonder what terms youth have and can generate for self-accomplished deaths. In the next section we offer a set of examples from historical, philosophical, and cross-cultural contexts which can disrupt our static conceptions of suicide, or at least give us a chance to watch how medicalized discourse functions to categorize deaths, stabilize their meaning, and border off undecidability.

\section{Difference, Movement, and Multiplicity}

Set against the drive to pin down the language of suicide and generate categories of certainty within mainstream suicidology, such as efforts to develop a precise nomenclature of terms distinguishing suicide from other self-harming phenomena (Silverman, Berman, Sanddal, O’Carroll, \& Joiner, 2007), our project is designed to open up possibilities for creative and innovative thinking, particularly by youth. To this end, we propose to disrupt the flows of the 
International Journal of Child, Youth and Family Studies (2014) 1: 180-203

dominant discourse of suicide through the exposure of multiple textual possibilities related to ending one's life and then explore how an approach grounded in an ontology of difference can more adequately account for youth as a life force capable of negotiating discourse in a process of ongoing subject formation. Building on this notion, the following section offers diverse perspectives related to suicide in order to reveal the jostling of power at work in understanding different forms of death. We argue that these perspectives can act as enabling investments that can be offered without expectation or compulsion when youth are viewed as creative and capable. As subjugated knowledges, the examples can be circulated within the dominant machine to make its processes, failings, and escape routes more visible. We wonder what conversations regarding suicide might emerge when youth have an opportunity to discuss a variety of perspectives and create new thought.

\section{Self-sacrifice, Protest, and Ritual}

Self-immolation, which refers to the burning of one's own body, has been understood as a form of protest, ritual, self-sacrifice, martyrdom, devotion, or renouncement. In the strictest sense of the term, self-immolation refers to self-sacrifice (from the Latin molare which refers to making a sacrifice of grain) and has only recently been used to specifically denote autocremation (Benn, 2007). In a Buddhist context, self-immolation is generally thought to be an enactment of the ideal of "being detached from the deluded notion of a self" (p. 9) and have been enacted through a variety of forms such as auto-cremation, drowning, feeding the body to animals, jumping from cliffs, and death by starvation. Examples include Jain practices of fasting until death (Fasting, n.d., Jainism, n.d.) and the Buddha's sacrifice to save a tigress in the Jataka tales.

Self-immolation also has a long history as a form of social and or political protest. Famously, Buddhist monk Thich Quang Duc, sitting in the lotus position, burned himself on a busy intersection in Vietnam to protest the persecution of other Buddhists in the country. The photographs by Malcolm Brown, which captured this burning of the body, are said to have contributed to the fall of the Diem regime. In the context of Tibetan monks who continue setting themselves on fire in protest of the continued Chinese occupation of Tibet, Jamyang Norbu (2012), Tibetan political activist and writer, refuses the interpretation that monks and nuns give up their life because of despair over the loss of their lands and freedoms but rather insists that self-immolations in Tibet be seen as an act done for the welfare, freedom, and independence of the Tibetan people. During the year that we wrote this paper (2012) there were nearly 50 confirmed self-immolations in Tibet (International Tibet Network, 2012). 

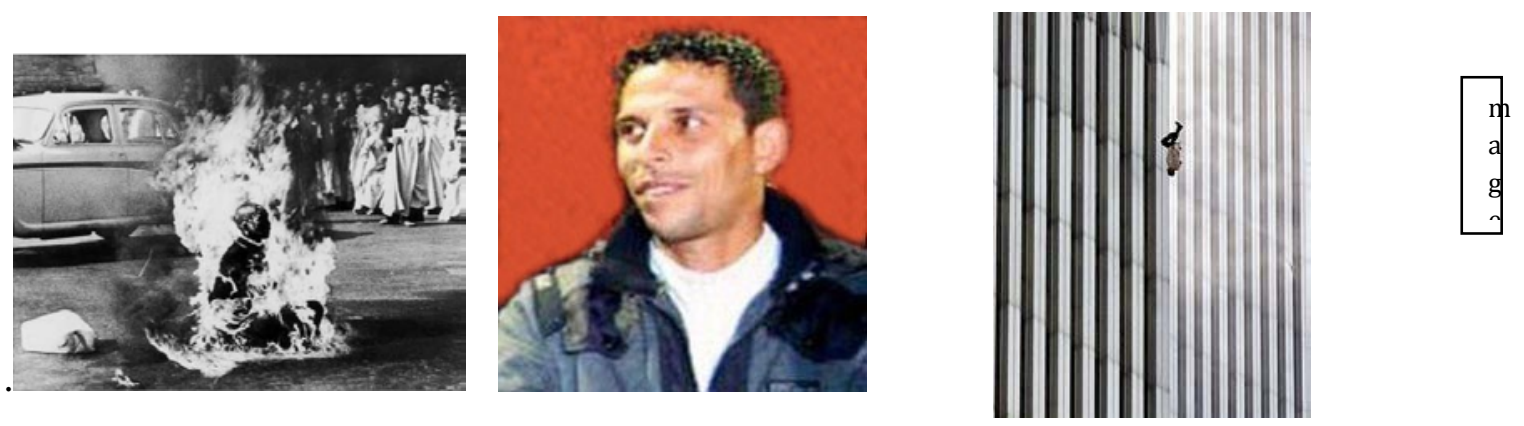

\section{Left: Thich Quang Duc; Middle: Tarek Bouazizi; Right: 9/11 Falling Man}

In another contemporary politicized context, Tarek Mohamed Bouazizi's self-immolation is understood by many as directly, although not intentionally, related to the 2012 uprisings across the Middle East. Bouazizi, in protest of police corruption and harassment in Tunisia, burnt his body outside provincial headquarters after being refused a hearing in regard to a complaint he wished to make against the police. Bouazizi's self-immolation has been interpreted by some as resulting from personal humiliation and hopelessness; however, for others the act is interpreted as a symbol of protest and a "declaration in defense of freedom" and an inspiration for those who revolted during the Arab Spring (Dowd, 2012, p. 2).

\section{Hate Kills}

Vikki Reynolds (2012) provides an ethically resolute counter-position to the pathologizing, individualizing, or glorifying of suicide, while also highlighting important political aspects of deaths understood as suicide. Speaking from a stance of social justice and anti-oppression, Reynolds vehemently challenges the very notion that people kill themselves, and instead holds herself accountable to those that have lost their lives by naming "hate" as that which has done the killing. In this sense, what is generally called suicide is not an individual act by any means, but rather a response to oppression, discrimination, or other forms of injustice. Reynolds (2012) offers the tools of anti-oppression analysis and language analysis in the place of psychometrics and the assessment of individual pathology, and she does so to the point that it is difficult for her to even say the word "suicide" because it is "constructed so individually" (p. 2). She argues that it is ethically necessary to resist the individualization of suicide:

This isn't something that happens to one person, and it's not something that one person does. Nobody kills themselves - these things do not happen in isolation. But always, things are in a context and because we live in a society that has not delivered on the promises of social justice, which we are well qualified and able to deliver, we always have to structure into our analysis of a person's death, the context of social injustice in which they lived. (pp. 2-3)

Reynolds (2012) argues that the word "suicide" obscures the context of injustice that a person has suffered. Once detached from context, suicide becomes associated with the mental state of the individual, usually as either depressed or anxious, while the social context of 
International Journal of Child, Youth and Family Studies (2014) 1: 180-203

injustice, as well as the responsibility of the perpetrators of injustice, disappears from the analysis. Furthermore, the totalizing word "suicide" also obscures the resistance that the victim of the injustice had enacted, and instead posits blame or shame for their acts. Reynolds' approach calls for a contextualized, historicized, and politicized reading of any action, most particularly those resulting in the harm or death of people. Furthermore, a social justice approach to suicide also suggests that we never "sit alone with suicide" (p. 7) but rather belong to a group of practitioners, theorists, and lay people who resist social injustice in its every form.

\section{Suicide as Post-colonial Disorder}

Rates of suicide among Indigenous youth are estimated to be five or six times higher than the general population (Kirmayer et al., 2007). There is also great variation in suicide rates across communities, with some First Nations reporting zero or very low rates of suicide (Chandler \& Lalonde, 1998). Efforts to understand the disproportionately high rates of youth suicide among First Nations, Inuit, and Métis peoples in Canada have often emphasized the damaging and persistent effects of colonization, including assimilationist policies, residential schools, intergenerational trauma, theft of land, and a systematic undermining of Indigenous peoples' rights to parent their own children, speak their own language, or govern their own communities (Kral, 2012).

In a recent study, Kral (2012) notes that suicide rates among Inuit youth have steadily increased since the 1980s. At one level, such high rates of suicide can be conceptualized as a form of protest against the damaging effects of the colonial encounter with the Canadian government. During the 1950s and 1960s, Inuit were relocated from the land to organized settlements and children were forced to attend residential schools, many of which were run by Christian missionaries who abused the children in their charge. As Kral notes, "Their subjectivities were shaped by the colonial madness of some missionaries. These schools were also assimilation factories that created gaps between children and their parents” (p. 312).

By recognizing suicide among Inuit youth as a response to the violent colonial logic of the "government era" which led to intergenerational segregation, as well as disruptions to traditional parenting, kinship, and romantic affiliations, suicide among Inuit youth can be read as a form of “post colonial disorder” (Delvecchio Good, Hyde, Pinto, \& Good, 2008). Viewed in this way, suicide prevention strategies that directly engage young people and local community members in actions and responses that have community control and decolonization at their centre are likely to be transformative. Preliminary evidence suggests that rates of youth suicide in those Inuit communities that took direct and local control over the problem are declining (Kral, 2012). Such a community-driven approach is in stark contrast to efforts that are imposed from outside, and which centre the expertise of psychologists, psychiatrists, and other specialists (Kral). Participatory forms of research and social change efforts that are rooted in collective understandings of distress and healing, and which directly engage with colonial-settler relations of power are thought to hold much promise for a re-imagined view of youth suicide prevention (see, for example, Wexler, 2006). 
International Journal of Child, Youth and Family Studies (2014) 1: 180-203

\section{Suicide as a Philosophical Problem}

Western philosophy and psychology have not remained silent on the subject of suicide as biomedical models have come to dominate. We provide a brief and incomplete survey of some of the trajectories of thought in Western philosophy and psychology here as counterpoints to the biomedical model. Our goal is not to provide comprehensive accounts but to argue that interest, creativity, and play can be counterpoints to a discourse that forecloses, reduces, and works towards singular meaning.

As a philosophical problem, in his 1942 classic The Myth of Sisyphus, the existentialist Albert Camus (1942) considers meaninglessness, absurdity, and the conditions under which suicide might be warranted. He ends his essay by proposing that life be lived in revolt of the absurdity of human existence and not avoided through suicide. Revolt, in this sense, is an empowered attitude towards the conditions of existence: The meaning of life is to grapple with its meaninglessness and suicide would be the rejection of such a task. Along similar existential lines, Jean Amery wrote of the misfortunes of the human condition and the escape of them through voluntary death (West, n.d.). In contrast to Camus, Amery argues for the possibility of legitimate reasons for choosing death while, at the same time, comments on the difficulty of fully comprehending the choice of death in psychological terms. For Amery, suicide is a legitimate and dignified escape or release from a miserable, helpless, or painful existence.

Michel Foucault's life and thought also offers a complicated perspective on suicide. ${ }^{5}$ Given the material fact that Foucault died of AIDS at the age of 57, authors such as Miller (1993) frame Foucault's openly risky sexual activity within a lifelong contemplation of death and suicide. Other authors such as Harper (2012), however, argue that Foucault's philosophy collapses simplistic distinctions between life, death, and suicide. Miller combines accounts of Foucault's substance use and sexual behaviour with interpretations of his philosophy to speculate that Foucault may have seen AIDS as a way of living passionately and embracing a death that would be singular and authentic. Harper, on the other hand, while also drawing on Foucault's notions of passion and embrace, intensities and singularities, offers a Foucauldian perspective of suicide as a meditation or practice of life. Harper explains that when considered through Foucault's notion of preparation, suicide as a meditation on life can be a transformative experience of passion. As a question related to how one might live, Harper reminds us that in Technologies of the Self (1988), Foucault asks how we as subjects have been compelled to decipher ourselves in regard to what is forbidden. The practice of reflecting on suicide, therefore, becomes for Foucault a technology for liberating the self from systems of control.

Although psychoanalysis was very much involved in the development of contemporary notions of suicide, it is interesting to note Freud's theorizations, particularly in their evolving character. Freud in 1910 understood suicide as a defense of the ego in the circumstance that the life instincts (libido) were being overwhelmed by sexual drives and then, in 1917, explained suicide in terms of melancholia (Freud, 1957) and the introjection of the hatred felt for a lost

\footnotetext{
${ }^{5}$ Foucault's philosophy and ways of life related to suicide are well beyond the scope of this paper. Our juxtaposition of Harper (2012) and Miller (1993) is offered as an opening gambit for the interested reader. Foucault's (1979/1996) The Simplest of Pleasures and (1988) Technologies of the Self are two entry points for his direct engagement on the subject.
} 
International Journal of Child, Youth and Family Studies (2014) 1: 180-203

object (de Mijolla-Mellor, 2005). As part of a major revision of his thinking, Freud later (1920/2010) introduces the idea of the death drive in reference to the "urge in organic life to restore an early state of things” (p. 308) or for an animal to die on its own terms.

\section{The Falling Man}

The events infamously known as 9/11 are equally infamously associated with suicide, death, despair, and tragedy. While the collapse of the World Trade Center (WTC) has for the most part been attributed to Muslim extremists, there have, nonetheless, been no shortages of conspiracy theories linking the collapse of the world trade towers to the U.S. government (Mole, 2006). In the case of the Muslim extremist explanation for the events, conceptualizations of suicide missions (Elster, 2005) or religious martyrs are invoked and attitudes related to those understandings vary considerably across the globe. A less discussed dimension of the 9/11 events, an aspect that was actually blacked-out of mainstream media during and immediately following the events, is what has come to be known as "The Falling Man". While referring to a photograph of one man falling from the North Tower of the WTC, this represents the over 200 people (up to $7 \%$ of those who died at 9/11) who fell or jumped to their deaths prior to the complete collapse of the towers (Singer, 2006). Videos of the day captured hundreds of dark shadows falling from the two WTC buildings: "they jumped alone, in pairs and in groups" (USA Today, 2002). Although $9 / 11$ is by far the most photographed and videotaped day in history, the Falling Man, or any other photographs capturing the hundreds of people who died by jumping/falling on September 11th, have been rendered taboo and virtually banned from mainstream media outlets (Linfield, 2011). Many argue over the name "jumpers" as the term generally relates to premeditated suicides and others deliberate over the notion of choice in a situation such as the one those people found themselves in.

\section{Guardrails and Guardians}

In analyzing the diverse knowledges related to end of life choices, deconstruction can very easily be critiqued as preventing stability or a grounded approach to knowledge. We agree and are proposing that any compulsory form of understanding suicide would need to either: (a) reduce these various experiences and explanations to psychopathology; or (b) declare that they are not technically suicides but something else. In both cases a coherent discourse on "suicide" is preserved. Deconstruction, by disrupting these processes of recuperation, can open up a field of study to dangerous possibilities and unpredictable meanderings, as, undoubtedly, we will be charged with doing. On the one hand, we acknowledge that our work thus far tends towards destabilizing the guardrails that society has instituted to protect their most vulnerable people. On the other hand, however, deconstruction, and post-structural thought more generally, can also be seen as protecting the vitality and movement of life from overdetermination, stagnation, and constraint. In this second view, deconstruction questions life worthy of its name and protects against the excesses of oppression, fanaticism, and domination, which muster in places where power goes unquestioned. In the final section of this paper, we work with another post-structural aggregation to propose a life affirming ontology which can help us to rethink our engagements with young people and think otherwise the compulsory ontology of pathology. 
International Journal of Child, Youth and Family Studies (2014) 1: 180-203

\section{Ontologies of Difference and Becoming}

Philosophy in the Western tradition, from Plato through to structuralism, has consistently understood ontology as the practice of discovering, identifying, and explaining what there is in the world. A realist ontology, which is based on the notion that there is a reality "out there" which can be sensed, known, and represented symbolically (i.e., through language and/or mathematics), is typically accepted as a truth. The current orthodoxy for thinking about suicidal individuals demands that they be understood through an ontology of identity: one that reduces difference and institutes a necessary relationship between the suicidal and the pathological. Identified thus, individuals are regarded as at risk or dangerous and in need of surveillance, management, and control. Our use of post-structural critique thus far has demonstrated the cracks in this framework. We are now left to explore the productive and generative possibilities that may exist in the spaces opened by these ruptures. For this task, we turn to Deleuze and Guattari who help us render these exposed failures as starting points in responding to the question of how life might be lived otherwise.

Deleuze (1968/1994) and Deleuze and Guattari (1972/2000; 1980/2004) generate ontologies rather than critique them. This is because ontology, in their hands, is not about seeking essences, truths, and identities, but rather is about creating adequate concepts for the radical difference at play in existence. This is an ontology that is always entangled with our engagements in it: an immanent play in which thought, subjectivity, materiality, and the events of existence are constitutive of one another. In a sense, Deleuze and Guattari return to "a world and a universe that may be more alive than we have been led to think” (May, 2005, p. 73).

May (2005) describes Deleuze as pushing the ontological project to its limit and in so doing, finding "the question of how one might live to be raised afresh and ready to offer surprising answers” (p. 16). To begin with, Deleuze (1968/1994) flips traditional ontology by treating reality as something that is created rather than discovered. Whereas other 20th century continental philosophers enacted skepticism towards the project of discovering truth and identity, Deleuze, building on Spinoza's ontology of immanence, offers us a vast number of ontologies and entities that shift, mutate, and wreak havoc on any project of unity and identity. May explains that when ontology is conflated with identity, the articulation of the essence of what is actually there, in our case suicide, depends on the stability of that which is being identified (a common experience) as well as the stability of the concept being used to describe it (the singular term "suicide"). As we have seen, the stability of both the experience and the term are highly contested from a post-structural perspective and inaugurate a crisis for the human sciences (such as suicidology). We take up Deleuze and Guattari (1972/2000; 1980/2004) at this point to offer a possible way forward: the crisis of ontology not as impasse but as a starting point.

By positing difference at the substantive level of all that there is, Deleuze (1968/1994) challenges us to conceptualize thinking as a creative impetus which can focus energy towards life-affirming projects and the creation of possible worlds. Rather than continuing a critique that condemns modernism as misguided and ultimately limiting possibilities for living, Deleuze extends a philosophic current, rooted in Spinoza, which proposes that conceptual creativity produces possibilities for life. If all of existence is the actualization of difference, it is our 
capacity to think and live differently which makes life livable. In the hands of Deleuze, ontology is a way of affirming life, difference, and the interconnections and intensities of thought, materiality, and affect. Rather than striving for a truth of being or the identity of what exists, Deleuze and Guattari work to perpetually "open the question of how one might live to new vistas” (May, 2005, p. 17). Rather than thought which discovers and captures, Deleuze and Guattari (1980/2003) propose thinking as creativity, invention, improvisation, and an engine for life. Thinking suicide in this way repositions youth from passive recipients of knowledge practices to active creators of life and knowledge: lives and thoughts worth living.

Importantly, Deleuze and Guattari (1972/2000; 1980/2004) do not privilege the human individual as the primary unit of analysis in their ontologies and therefore life and death are not solely understood in terms of a human life. May (2005) explains that for Deleuze and Guattari, the adequacy of focusing on human life, or any other way of conceptualizing life, depends on the contributions that the perspective has for living:

The question of how one might live, then, is not simply a question of how a human being might go about creating his or her future. It is that, too. But it is not merely that. As a question of ontology, it concerns the creation of concepts of difference that allow us to consider living at different levels. Among these levels we may find a variety of understandings of ourselves, and this variety of understandings may open up a variety of futures to be lived. (p. 24)

How then are we to think of suicide and our engagements with youth through such an ontology? Braidotti (2009), working in the post-structural tradition of Deleuze and Guattari, writes "no reason other than the sterility of habit justifies the emphasis on death as the horizon for the discussions on the limits of our understanding of the human. Why not look at the affirmative aspects of exactly the same issue?” (p. 40). Furthermore, she argues that representational thinking, which equates (or at least claims a correspondence between) concepts and things out in the world, is an outdated model for thinking of the subjects we have become. Working to extend Deleuzian ontologies of immanence and difference, Braidotti re-inscribes the Greek concept of Zoe as the incessant vitality of life as unremitting becomings. This approach to understanding life dissolves the notion of an individual human subject facing mortality and reinscribes subjectivity as a site of multiple belongings and becomings. The human organism in this view is an embodied affective intersection of multiple forces, intensities, and processes. In terms of theorizing suicide from such a neo-vitalist position, we need particular, local, and accurate descriptions of the intersecting forces which produce the contradictions, possibilities, and actualities of singular experiences of life and death. What if the term "suicide” were rejected in its capacity to flatten out singularity of each manifested event? What if youth participated in the cartographic projects of mapping each event anew? What if our incorporations into the systems, assemblages, and processes that formed around end of life decisions were evaluated in terms of their generative and affirmative force rather than surveillance, prevention, and control?

By grounding relational practices in an ontology of difference, the multiplicities previously reduced and repressed by the totalizing concept "suicide" become open to the play of singular events which exceed static representation. Furthermore, our practices of engaging become radical projects of transformation and creation: events in a dynamic flow of the 
International Journal of Child, Youth and Family Studies (2014) 1: 180-203

production of difference. Braidotti's (2006, 2009) suggestions inspire us to claim that it is in the very attempt to eliminate, control, or stabilize "suicide", to apply care-as-vigil, that life forces get smothered. As a life-generating practice, the gift of care opens a joining-with and a freedom-tobecome which can affirm and activate the life forces needed to sustain or endure hardship.

\section{Conclusion: Towards Multiple, Affirmative Engagements with Life}

Post-structural critique and creativity invite us to problematize and disengage from notions of isolated selves and others which call for containment and categorization. We are asked instead to experiment with new organizations of forces. We are asked to think in terms of what can be produced, not what can be prevented. Active and creative forces produce life, expression, and positive affect; whereas death is synonymous with forces of containment, control, restriction, and reactivity. Self-preservation or sustainability, therefore, is the free flowing of Zoe and active forces, which mobilize affect and produce life-affirming experiences and connections.

Ethical practice from this perspective is therefore the capacity to be positively affected by enjoyment and pleasure, as well as the capacity to endure the pain and vulnerabilities implicit in relationship. Paradoxically, this affirmative ethic that Braidotti (2009) has inspired implies the possibility of ending one's own life when existence becomes degraded or unbearable. The impersonality of life, the view that all subjects are constituted through impersonal forces and flows of life and power, implies that death is ultimately not one's own (Braidotti). Life, death, and the subject are recurring happenings in the flows of Zoe and becoming: exceeded by any individual.

It is our hope that our joint writing project - to think the other side of suicide - has opened up new conversational spaces for theorizing youth suicide and for rethinking the conventional project of prevention. Instead of the avoidance, suppression, control, disgust, resignation, or rejection of suffering and death, it is the transformative potential of affirming life in all its difference that we seek. Braidotti (2006) writes, "paradoxically, it is those who have already cracked up a bit, those who have suffered pain and injury, who are better placed to take the lead in the process of ethical transformation" (p. 349). What would it be like to privilege the knowledge of those marginalized by social difference and suffering and to join in a productive connection with their bodies, affects, thoughts, expressions and experiences? To be produced in connection with them: to relate, endure, and transform with them? To become undone ourselves and not know what will be produced next? What if, as Braidotti suggests, the limits of the endurance of pain which is suicide, the "I can't take it anymore!" is seen as "the threshold and hence the condition of possibility for creative encounters and productive changes” (p. 349). What would it be to privilege difference, change, and an undisclosed future above identity, certainty, standardization, and control? What does a suicide bring together? How is it put together? How does it come apart or break down? How can what has come together become (thought) otherwise? What would it be to affirm the life that is immanent to all suicides: to affect and allow ourselves to be affected, to move with all that is active in life and death? In their book What is Philosophy?, Deleuze and Guattari (1994/2003) reflect back on a lifetime of thinking otherwise to claim that philosophy is the creation of concepts. We hope that this paper has inspired our readers to imagine what may become possible when youth and practitioners are mutually engaged as co-creators of their own thoughts, lives, practices, and deaths. 
International Journal of Child, Youth and Family Studies (2014) 1: 180-203

\section{References}

Benn, J. A. (2007). Burning for the Buddha: Self-immolation in Chinese Buddhism. Hawaii: Hawaii University Press.

Braidotti, R. (2006). Affirmation versus vulnerability: On contemporary ethical debates. Symposium: Canadian Journal of Continental Philosophy, 10(1), 235-254.

Braidotti, R. (2009). Transpositions. Cambridge: Polity Press.

Caputo, J. (Ed.). (1997). Deconstruction in a nutshell: In conversation with Jacques Derrida. New York: Fordham University Press. http://dx.doi.org/10.5860/choice.34-6206

Camus, A. (1955). The myth of Sisyphus and other essays. New York: Alfred A. Knopf.

Chandler, M., \& Lalonde, C. (1998). Cultural continuity as a hedge against suicide in Canada’s First Nations. Transcultural Psychiatry, 35(2), 191-219. http://dx.doi.org/10.1177/136346159803500202

Dean, M. (2012). The story of Amanda Todd. The New Yorker. Retrieved from http://www.newyorker.com/online/blogs/culture/2012/10/amanda-todd-michael-brutschand-free-speech-online.html?mbid=nl_Daily\%20

de Mijolla-Mellor, S. (2005). Suicide. In A. de Mijolla (Ed.), International Dictionary of Psychoanalysis (pp. 1687-1688). New York: Thomson.

de Saussure, F. (1959). Course in general linguistics (W. Baskin, Trans.). New York: Philosophical Library.

Deleuze, G. (1994). Difference and repetition (P. Patton, Trans.). New York: Columbia University Press. (Original work published 1968)

Deleuze, G., \& Guattari, F. (2000). Anti-Oedipus: Capitalism and schizophrenia (R. Hurley, M. Seem, \& H. R. Lane, Trans.). Minneapolis: University of Minnesota Press. (Original work published, 1972)

Deleuze, G., \& Guattari, F. (2003). What is philosophy? (G. Burchell \& H. Tomlinson, Trans.). London: Verso. (Original work published, 1994)

Deleuze, G., \& Guattari, F. (2004). A thousand plateaus: Capitalism and schizophrenia (B. Massumi, Trans.). New York: Continuum. (Original work published, 1980)

Delvecchio Good, M., Hyde, S., Pinto, S., \& Good, B. (2008). Postcolonial disorders. Berkeley, CA: University of California Press. http:/dx.doi.org/10.1525/california/9780520252233.001.0001

Derrida, J. (1976). Of grammatology (G. C. Spivak, Trans.). Baltimore: John Hopkins University Press. (Original work published, 1967)

Derrida, J. (1978). Structure, sign and play in discourse of the human sciences. In Writing and difference (A. Bass, Trans.) (p. 351-370). Chicago: University of Chicago. (Original work published 1966)

Derrida, J. (1992). Given time: Counterfeit money (P. Kamuf, Trans.). Chicago: Chicago University Press.

Derrida, J. (1995). The gift of death (D. Wills, Trans.). Chicago: Chicago University Press. 
International Journal of Child, Youth and Family Studies (2014) 1: 180-203

Diprose, R. (2008). Biopolitical technologies of prevention. Health Sociology Review, 17(2), 141-150. http://dx.doi.org/10.5172/hesr.451.17.2.141

Dowd, A. W. (2012). Bouazizi's revolution. Retrieved from http://www.fraserinstitute.org/publicationdisplay.aspx?id=2147484074\&terms=bouazizi

Elster, J. (2005). Motivations and beliefs in suicide missions. In D. Gambetta (Ed.), Making sense of suicide sissions (pp. 233-258). Oxford: Oxford University Press. http://dx.doi.org/10.1093/acprof:oso/9780199276998.003.0007

Fasting. (n.d.). In $B B C$ Religions. Retrieved from http://www.bbc.co.uk/religion/religions/jainism/customs/fasting_1.shtml

Foucault, M. (1978). The history of sexuality. Volume 1: An introduction (R. Hurley, Trans.). New York, Pantheon Books.

Foucault, M. (1980). Two lectures. In C. Gordon (Ed.), Power/knowledge: Selected interviews and other writings, 1972-1977. Brighton, UK: Harvester Press. (Original work published 1976)

Foucault, M. (1988). Technologies of the self. In L. H. Martin, H. Gutman, \& P. H. Hutton (Eds.), Technologies of the self: A seminar with Michel Foucault (pp. 16-49). Amherst, MA: University of Massachusetts Press.

Foucault, M. (1996). The simplest of pleasures (M. Riegle \& G. Barbedette, Trans.). In S. Lotringer (Ed.), Foucault Live: Collected Interviews, 1961-1984 (pp. 295-297). New York: Semiotext(e). (Original work published 1979)

Fox, N. (1995). Postmodern perspectives on care: The vigil and the gift. Critical Social Policy, 15(44/45), 107-125. http://dx.doi.org/10.1177/026101839501504407

Freud, S. (2010). Beyond the pleasure principle (J. Strachey Trans.). Seattle, WA: Pacific Publishing Studio. (Original work published 1920)

Freud, S. (1957). Mourning and melancholia. In J. Strachey (Ed. \& Trans.), The standard edition of the complete psychological works of Sigmund Freud (Vol. 14, 1914-1916: On the history of the psycho-analytic movement, papers on metapsychology and other works, pp. 23-238). London: The Hogarth Press. (Original work published 1917)

Fullagar, S. (2003). Wasted lives: The social dynamics of shame and youth suicide. Journal of Sociology, 39(3), 291-307.http://dx.doi.org/10.1177/0004869003035076

Harper, M. P. (2012). Bewilderingly, forcefully: Drawing the line outside. Journal of Philosophy: A Cross-Disciplinary Inquiry, 7(17), 60-69. http://dx.doi.org/10.5840/jphilnepal20127176

International Tibet Network. (2012, October). Self-immolations increase as Chinese leadership changes. Retrieved from http://tibetnetwork.org/self-immolations-increase-as-chineseleadership-changes/

Jainsism. (n.d.). In Encyclopaedia Britanica online. Retrieved from http://www.britannica.com/EBchecked/topic/299478/Jainism

Jaworski, K. (2003). Suicide and gender: Reading suicide through Butler's notion of performativity. Journal of Australian Studies, 27(76), 137-146. http://dx.doi.org/10.1080/14443050309387832 
International Journal of Child, Youth and Family Studies (2014) 1: 180-203

Jaworski, K. (2010). The author, agency and suicide. Social Identities, 16(5), 675-687. http://dx.doi.org/10.1080/13504630.2010.509572

Kirmayer, L., Brass, G., Holton, T., Paul, K. Simpson, C., \& Tait, C. (2007). Suicide among Aboriginal people in Canada. Ottawa, ON: Aboriginal Healing Foundation.

Kral, M. (2012). Postcolonial suicide among Inuit in Arctic Canada. Culture, Medicine and Psychiatry, 36(2), 306-325. http://dx.doi.org/10.1007/s11013-012-9253-3

Kushner, H. I. (1986). American psychiatry and the cause of suicide, 1877-1917. Bulletin of the History of Medicine 60(1), 36-58.

Kushner, H. I. (2009). Suicide, gender, and the fear of modernity. In J. Weaver \& D. Write (Eds.), Histories of suicide: International perspectives on self-destruction in the modern world (pp. 19-52). Toronto: Toronto University Press.

Law, J. (2004). After method: Mess in social science research. New York: Routledge.

Lindfield, S. (2011, August 27). Jumpers. New York Magazine, Encyclopedia of 9/11. Retrieved from http://nymag.com/news/9-11/10th-anniversary/jumpers/

Marsh, I. (2010), Suicide, Foucault, history and truth. Cambridge: Cambridge University Press.

Mav, T. (2005). Gilles Deleuze: An introduction. Cambridge: Cambridge University Press.

http://dx.doi.org/10.1017//cbo9781139165419

Miles, M. (2001). Plato on suicide ("Phaedo” 60C-63C). Phoenix, 55(3/4), 244-258.

http://dx.doi.org/10.2307/1089120

Miller, J. (1993). The Passion of Michel Foucault. Cambridge, MA: Harvard University Press.

Mole, P. (2006). 9/11 conspiracy theories: The 9/11 truth movement in perspective. Skeptic 6(2). Retrieved from http://www.skeptic.com/eskeptic/06-09-11/

Murray, A. (1998a). Suicide in the middle ages: Volume I. New York: Oxford University Press.

Murray, A. (1998b). Suicide in the middle ages: Volume II. New York: Oxford University Press.

Norbu, J. (2012). Self-immolation and Buddhism. http://www.jamyangnorbu.com/blog/2012/01/03/self-immolation-and-buddhism/

Range, L., \& Leach, M. (1998). Gender, culture and suicidal behaviour: A feminist critique of theories and research. Suicide and Life Threatening Behavior, 28(1), 24-36.

Reynolds, V. (2008). An ethic of resistance: Front line worker as activist. BWSS Newsletter, 19(1), 5.

Reynolds, V. (2012). Hate Kills. Retrieved from http://discoursesofprevention.com/postsymposium-activities/

Rose, N. (1999). Governing the soul: The shaping of the private self (2nd ed.). London: Free Association Books.

Silverman, M., Berman, A., Sanddal, N., O’Carroll, P. \& Joiner, T. (2007). Re-building the tower of Babel: A revised nomenclature for the study of suicide and suicidal behaviors. Part 2. Suicide-related ideations, communications and behaviors. Suicide and Life Threatening Behaviors, 37(3), 264-277. http://dx.doi.org/10.1521/suli.2007.37.3.264

Singer, H. (Director). (2006). 9/11: The falling man [Television documentary]. United Kingdom: Darlow Smithson Productions. 
International Journal of Child, Youth and Family Studies (2014) 1: 180-203

Statistics Canada. (2012). Suicides and suicide rate, by sex and by age group. Retrieved January 23, 2012 from http://www40.statcan.gc.ca/101/cst01/hlth66a-eng.htm?sdi=suicide

Stephenson, C., \& Cutcliffe, J. (2006). Problematizing special observation in psychiatry: Foucault, archaeology, geneaology, discourse and power/knowledge. Journal of Psychiatric and Mental Health Nursing, 13(6), 713-721. http:/dx.doi.org/10.1111/j.1365-2850.2006.01023.x

Tatz, C. (2001). Aboriginal suicide is different: A portrait of life and self-destruction. Canberra, Australia: Aboriginal Studies Press.

USA Today. (2002, September, 11). Desperation forced a horrific decision. Retrieved from http://www.usatoday.com/news/sept11/2002-09-02-jumper_x.htm

West, A. (n.d.). Hope as insult and provocation. Retrieved from http://asymptotejournal.com/article.php?cat=Special_Feature\&id=81\&curr_index =28\&cu rPage $=$ current

Wexler, L. M. (2006). Inupiat youth suicide and culture loss: Changing community conversations for prevention. Social Science \& Medicine, 63(11), 2938-2948. http://dx.doi.org/10.1016/j.socscimed.2006.07.022 